\title{
Constitutive Overexpression of Human Erythropoietin Protects the Mouse Retina against Induced But Not Inherited Retinal Degeneration
}

\author{
Christian Grimm, ${ }^{1}$ Andreas Wenzel, ${ }^{1}$ Dinu Stanescu, ${ }^{1}$ Marijana Samardzija, ${ }^{1}$ Svenja Hotop, ${ }^{1}$ Mathias Groszer, ${ }^{2}$ \\ Muna Naash, ${ }^{3}$ Max Gassmann, ${ }^{4}$ and Charlotte Remé ${ }^{1}$ \\ ${ }^{1}$ Laboratory for Retinal Cell Biology, University Eye Hospital, CH-8091 Zurich, Switzerland, ${ }^{2}$ Howard Hughes Medical Institute, University of California Los \\ Angeles, Los Angeles, California 90095, ${ }^{3}$ Department of Cell Biology, University of Oklahoma, Oklahoma City, Oklahoma 73104, and ${ }^{4}$ Institute of Veterinary \\ Physiology, University of Zurich, CH-8091 Zurich, Switzerland
}

\begin{abstract}
Elevation of erythropoietin (Epo) concentrations by hypoxic preconditioning or application of recombinant human Epo (huEpo) protects the mouse retina against light-induced degeneration by inhibiting photoreceptor cell apoptosis. Because photoreceptor apoptosis is also the common path to cell loss in retinal dystrophies such as retinitis pigmentosa (RP), we tested whether high levels of huEpo would reduce apoptotic cell death in two mouse models of human RP. We combined the two respective mutant mouse lines with a transgenic line (tg6) that constitutively overexpresses huEpo mainly in neural tissues. Transgenic expression of huEpo caused constitutively high levels of Epo in the retina and protected photoreceptors against light-induced degeneration; however, the presence of high levels of huEpo did not affect the course or the extent of retinal degeneration in a light-independent (rd1) and a light-accelerated (VPP) mouse model of RP. Similarly, repetitive intraperitoneal injections of recombinant huEpo did not protect the retina in the rd 1 and the VPP mouse. Lack of neuroprotection by Epo in the two models of inherited retinal degeneration was not caused by adaptational downregulation of Epo receptor. Our results suggest that apoptotic mechanisms during acute, light-induced photoreceptor cell death differ from those in genetically based retinal degeneration. Therapeutic intervention with cell death in inherited retinal degeneration may therefore require different drugs and treatments.
\end{abstract}

Key words: retinal degeneration; erythropoietin; apoptosis; neuroprotection; photoreceptor; transgene

\section{Introduction}

Retinitis pigmentosa (RP) and age-related macular degeneration (AMD) are major causes of severe visual impairment and blindness in the Western world. Common to both diseases is photoreceptor cell death by apoptosis (Portera Cailliau et al., 1994; Wong, 1994; Remé et al., 1998; Adler et al., 1999). Evidence points to light as a cofactor accelerating the disease progression (Taylor et al., 1990; Cruickshanks et al., 1993, 2001 Simons, 1993; Cideciyan et al., 1998), and some animal models for human retinal degenerations show higher light damage susceptibility than normal control animals (Sanyal and Hawkins, 1986; Wang et al., 1997; Chen et al., 1999a,b; LaVail et al., 1999; Organisciak et al.,

Received Dec. 5, 2003; accepted April 29, 2004.

This work was supported by the Swiss National Science Foundation, the Theodore Ott Foundation, the Hartmann Müller Foundation, the Foundation for Scientific Research of the University of Zurich, the VELUX Foundation (Glarus, Switzerland), Grant EY-10609 from the National Eye Institute, a Core Grant for Vision Research at the University of Oklahoma (EY12190), and a National Institutes of Health Grant P20 RR 017703 from the Center of Excellence in Biomedical Research Program of the National Center for Research Resources to the University of Oklahoma. D.S. was supported by "Aspirant Candidat Fonds National de la Recherche Scientifique Belge," Department of Ophthalmology, Centre Hôpitaux Universitaire Saint-Pierre (Brussels, Belgium). We thank C. Imsand, D. Greuter, G. Hoegger, and S. Keller for expert technical assistance.

Correspondence should be addressed to Christian Grimm, Laboratory for Retinal Cell Biology, University Eye Hospital, Frauenklinikstrasse 24, CH-8091 Zurich, Switzerland. E-mail: cgrimm@opht.unizh.ch.

DOI:10.1523/JNEUROSCI.1288-04.2004

Copyright $\odot 2004$ Society for Neuroscience $\quad$ 0270-6474/04/255651-08\$15.00/0
1999). Exposure to high levels of white light can thus be used as a model system to study signaling pathways during photoreceptor apoptosis and retinal degeneration (Remé et al., 1998).

Recently we showed that hypoxic preconditioning stabilizes the $\alpha$-subunit of the hypoxia-inducible transcription factor- 1 (HIF-1) in the retina. Subsequent binding of HIF- $1 \alpha$ (for review, see Hopfl et al., 2004) to its heterodimerization partner HIF-1 $\beta$ induces the retinal expression of erythropoietin (Epo) and of other HIF-1 target genes and transiently protects the mouse retina against the damaging effects of light exposure (Grimm et al., 2002). The application of recombinant human Epo (huEpo) mimics the effect of hypoxia, demonstrating that Epo is a main component of the neuroprotection observed (Grimm et al., 2002). The protective effect of hypoxic (and hyperoxic) oxygen levels has also been demonstrated in a rat model of continuous light exposure (Bowers et al., 2001), and the importance of oxygen and thus of oxygen-regulated tissue responses has been documented during retinal development, when physiological hypoxia may regulate cell death (Mervin and Stone, 2002). Furthermore, increased oxygen levels were shown to slow photoreceptor death in a rat model of retinal degeneration, whereas hypoxia accelerated cell death (Maslim et al., 1997; Valter et al., 1998).

To test whether Epo might prevent retinal degeneration in 
Table 1. Average Epo levels in retinas of wt, $\mathrm{tg} 6, \mathrm{rd} 1, \mathrm{VPP}, \mathrm{rd} 1 / \mathrm{tg} 6$, and VPP/tg6 mutant mice at different postnatal days as indicated

\begin{tabular}{|c|c|c|}
\hline Strain & Postnatal days & Epo (mIU /100 $\mu \mathrm{g})$ \\
\hline wt & 11 & 0.38 \\
\hline $\operatorname{tg} 6$ & 11 & 8.26 \\
\hline rd1 & 11 & 0.24 \\
\hline VPP & 11 & $<0.002$ \\
\hline $\mathrm{rd1} / \operatorname{tg} 6$ & 11 & 9.48 \\
\hline VPP / tg6 & 11 & 11.66 \\
\hline wt & 21 & 0.16 \\
\hline $\operatorname{tg} 6$ & 21 & 3.75 \\
\hline rd1 & 21 & 0.02 \\
\hline VPP & 21 & 0.04 \\
\hline $\mathrm{rd1} / \operatorname{tg} 6$ & 21 & 14.78 \\
\hline VPP / tg6 & 21 & 9.92 \\
\hline wt & 37 & 0.16 \\
\hline $\operatorname{tg} 6$ & 37 & 3.89 \\
\hline rd1 & 37 & $<0.002$ \\
\hline VPP & 37 & ND \\
\hline $\mathrm{rd1} / \operatorname{tg} 6$ & 37 & 8.19 \\
\hline VPP / tg 6 & 37 & ND \\
\hline
\end{tabular}

ND, Not determined. $n=2-5$ retinas.

models of inherited retinal disease, we used a transgenic mouse line (termed tg6) that constitutively overexpresses huEpo in an oxygen-independent manner preferentially in neuronal cells (Ruschitzka et al., 2000; Wiessner et al., 2001). Compared with wild-type (wt) controls, tg6 mice show 26-fold increased Epo levels in brain as well as a 12-fold elevation of Epo plasma levels (Wagner et al., 2001; Vogel et al., 2003). Here, heterozygous transgenic tg6 males were bred with two mouse models for human RP [ for recent reviews on retinal degeneration animal models, see Hafezi et al. (2000) and Chang et al. (2002)]. The rd1 mouse carries a mutation in the gene encoding the phosphodiesterase $\beta$-subunit causing a fast and light-independent degeneration of photoreceptors (Bowes et al., 1990). The VPP transgenic mouse strain harbors three mutations (V20G, P23H, P27L) in the rhodopsin gene (Naash et al., 1993), one of which (P23H) represents the most common cause for autosomal-dominant RP in the United States. In the VPP mouse, retinal degeneration is accelerated by light but nevertheless proceeds slower than in the $\mathrm{rd} 1$ mouse (Goto et al., 1996; Naash et al., 1996).

We show that transgene-derived Epo protects against photoreceptor apoptosis induced by acute light exposure. It does not protect against the mutation-based degenerations in rd 1 and VPP mice, however, although light is a cofactor accelerating photoreceptor degeneration in the latter. These results may be of importance with respect to potential clinical trials using Epo in patients with retinal dystrophies.

\section{Materials and Methods}

Mice. All procedures concerning animals were in accordance with the regulations of the Veterinary Authority of Zurich and with the statement of The Association for Research in Vision and Ophthalmology for the use of animals in research. Rpe65 variant at position 450 of the protein was determined by PCR using upstream primer 5 '-CACTGTGGTCTCTGCTATCTTC- $3^{\prime}$ and downstream primer $5^{\prime}$-GGTGCAGTTCCACTTCAGTT- $3^{\prime}$. The amplification product (674 bp) was digested with MwoI, which cuts the leucine variant yielding fragments of 236 and $437 \mathrm{bp}$. MwoI does not cut the sequence encoding methionine. With the exception of tg6 and wt mice used in the light damage and rhodopsin regeneration study (heterozygous variant: Rpe $65_{450 \mathrm{Leu} / \mathrm{Met}}$; see Results), all mice used were homozygous for the Rpe65 $5_{450 \mathrm{Met}}$ variant.

Induction and analysis of light damage. Light damage was induced in dark-adapted 3-, 4-, and 6- to 8-week-old mice with dilated pupils by
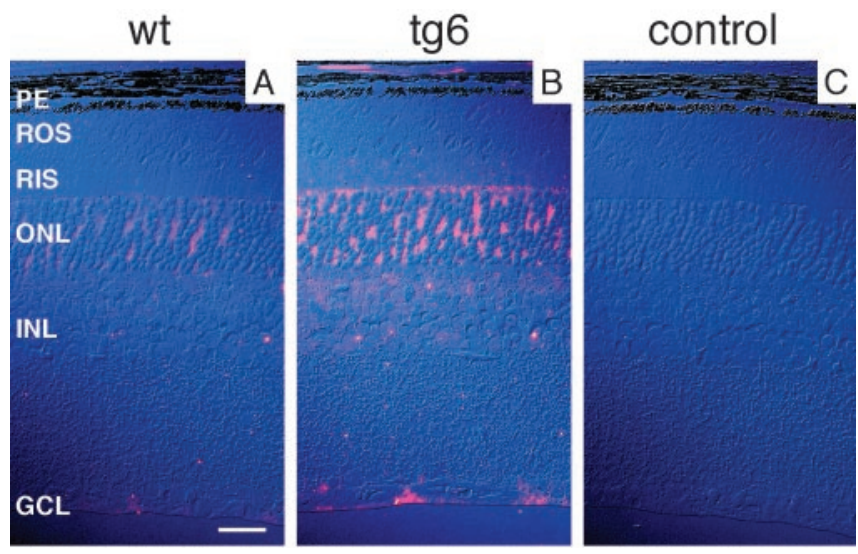

Figure 1. Expression and localization of Epo in the mouse retina. Retinas of wt $(A, C)$ and $\operatorname{tg} 6$ $(B)$ mice were fixed and stained using an antibody specific for Epo. Control was a wt retina incubated without primary antibody ( $C$. Both endogenous Epo and huEpo expressed from the transgene in tg6 localize to the ONL, INL, and GCL. PE, Pigment epithelium; ROS, rod outer segments; RIS, rod inner segments; ONL, outer nuclear layer; INL, inner nuclear layer; GCL, ganglion cell layer. Scale bar, $25 \mu \mathrm{m}$.

exposure to 13 klux of diffuse white fluorescent light for $120 \mathrm{~min}$ as described (Grimm et al., 2000). After $24 \mathrm{hr}$ in darkness, the extent of light damage was determined in the right retina using the Cell Death Detection Kit (Roche Diagnostics, Basel, Switzerland) according to the manufacturer's recommendation, and in the left eye the extent of light damage was determined by light microscopy as described (Kueng-Hitz et al., 2000).

Rhodopsin content and regeneration. The rhodopsin content was determined as described (Kueng-Hitz et al., 2000). Dark levels of rhodopsin were measured after $16 \mathrm{hr}$ of dark adaptation. To assess rhodopsin regeneration, dark-adapted mice, with dilated pupils, were exposed to white light (10 min, 5 klux). Rhodopsin was measured either immediately after light exposure or at $45 \mathrm{~min}$ in darkness.

Western blotting and ELISA. Retinas were homogenized in $100 \mathrm{~mm}$ Tris/HCl, $\mathrm{pH}$ 8.0, and analyzed for protein content using Bradford reagent. Standard SDS-PAGE and Western blotting were performed. For immunodetection, polyclonal rabbit anti-Epo receptor antibodies (sc697; Santa Cruz Biotechnology, Santa Cruz, CA) were applied, followed by an HRP-conjugated secondary anti-rabbit antibody (sc-2004; Santa Cruz Biotechnology), and immunoreactivity was visualized using the Renaissance-Western blot detection kit (PerkinElmer Life Sciences, Emeryville, CA).

Epo levels were determined with an ELISA kit according to the manufacturer's recommendations (R \& D Systems, Minneapolis, MN).

Immunohistochemistry. Eyes were enucleated and fixed in $2.5 \%$ glutaraldehyde/0.1 M phosphate buffer, $\mathrm{pH} 7.4$, for $4 \mathrm{hr}$ at $4^{\circ} \mathrm{C}$. Eyecups were cut temporal to nasal through the optic nerve head. Trimmed tissue was washed twice in $0.1 \mathrm{M}$ phosphate buffer, $\mathrm{pH} 7.4$, for $15 \mathrm{~min}$ followed by dehydration and embedding in Epon 812. Epoxy resin of $0.5 \mu \mathrm{m}$ tissue sections was removed by incubation for $7 \mathrm{~min}$ at room temperature in etching solution ( $2.4 \mathrm{M} \mathrm{KOH}, 66.6 \%$ methanol, $33.3 \%$ propylene oxide). Slides were washed once in $100 \%$ methanol, once in $50 \%$ methanol $/ 0.5 \times$ $\mathrm{PBS}$, and twice in PBS for $5 \mathrm{~min}$. Tissue was preincubated for $30 \mathrm{~min}$ with $10 \%$ normal goat serum (NGS) in PBS at room temperature followed by an overnight incubation with the primary anti-Epo antibody (AB-286NA, 1:200; R \& D Systems) in 3\% NGS at $4^{\circ} \mathrm{C}$. Slides were washed three times with PBS for 10 min each. Tissue was preincubated for $30 \mathrm{~min}$ in $10 \%$ NGS at room temperature. Cy3-conjugated anti-rabbit secondary antibody (Jackson ImmunoResearch, West Grove, PA) was applied for $80 \mathrm{~min}$ in $3 \% \mathrm{NGS}$ at room temperature. Sections were washed three times in PBS for 10 min each. Staining was analyzed with a fluorescence microscope (Axiovision, Zeiss) and documented using a digital imaging system.

Epo injections. One hundred international units of Epo (Recormon 

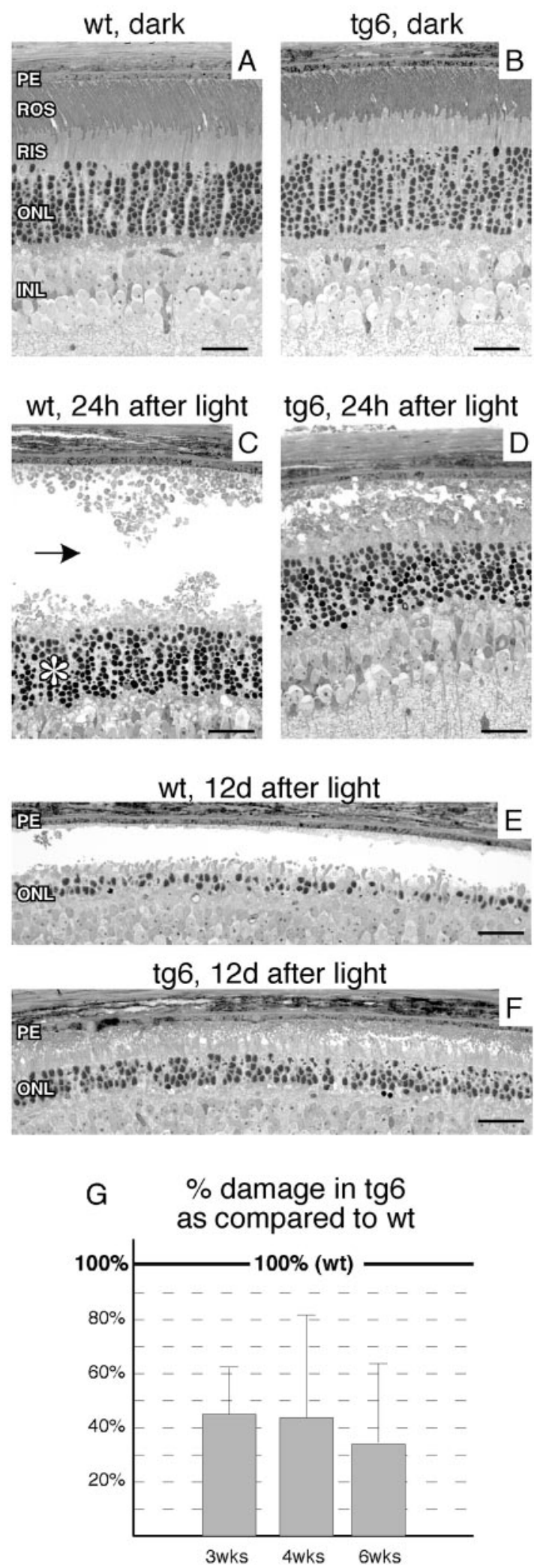

Figure 2. Light-induced retinal degeneration in wt and $\operatorname{tg} 6$ mice. $A$, Nonexposed wt retina. $B$, Nonexposed tg 6 retina. C, Most affected retinal area of a wt mouse $24 \mathrm{hr}$ after light exposure showing severe destruction of photoreceptor outer and inner segments $(\uparrow)$ and condensed nuclear chromatin $(*)$. D, Most affected retinal area of a $\operatorname{tg} 6$ mouse $24 \mathrm{hr}$ after light exposure. Lesions are qualitatively similar but distinctly less severe and the number of pyknotic nuclei is reduced. $E$, Most affected retinal area of a wt mouse $12 \mathrm{~d}$ after light exposure. One to two rows of photoreceptor nuclei are left. $F$, Most affected retinal area of a tg 6 mouse $12 \mathrm{~d}$ after light exposure. Four to five rows of photoreceptor nuclei are left. Affected region is smaller than in the
2000; Roche, Basel, Switzerland) in $0.9 \% \mathrm{NaCl}$ were injected intraperitoneally at postnatal day 11 (P11) (rd1 only), P13, P15, P17, and P19.

\section{Results}

\section{Overexpression and localization of huEpo in the retina}

HuEpo was expressed at highly elevated levels in the retina early during postnatal development in tg6 as well as in tg6/rd1 and tg6/VPP double-mutant mice (Table 1). The huEpo transgene expression localized mainly to the inner segments of photoreceptor cells: the outer nuclear layer (ONL), inner nuclear layer (INL), and ganglion cell layer (GCL). This localization was comparable with the endogenous Epo present in the wt retina (Fig. $1 A, B)$. The labeling was specific, because no signal was detected when the primary antibody was omitted (Fig. $1 C$ ) or when the immunoreaction was competed by preincubating the primary antibody with huEpo (data not shown). Expression of the transgene did not influence retinal morphology in tg6 mice (Figs. 1, 2, 5), suggesting that high levels of Epo and excessive erythrocytosis do not affect postnatal retinal development and developmental apoptosis.

\section{Overexpression of Epo protects against light-induced retinal degeneration}

Elevation of endogenous Epo levels by hypoxic preconditioning or exogenous application of recombinant huEpo protects against light-induced retinal degeneration (Grimm et al., 2002). Therefore, we tested whether high levels of huEpo constitutively expressed from the Epo transgene in tg6 mice would also be protective against light damage. After exposure to 13 klux of white light for $2 \mathrm{hr}$, cell death was firmly reduced in tg6 mice as compared with wt littermates (Fig. $2 A-F$ ). In wt animals, light exposure induced photoreceptor cell death in a large central area, with almost all photoreceptor nuclei showing condensed chromatin after $24 \mathrm{hr}$, an indicator of ongoing apoptosis (Fig. 2C). In contrast, the affected area in tg6 mice was smaller, and not all photoreceptor nuclei were pyknotic, even in the most affected region (Fig. 2D). When retinal morphology was analyzed $12 \mathrm{~d}$ after light exposure, wt mice showed one to two rows of surviving photoreceptor nuclei (Fig. 2E), whereas tg6 retinas retained four to five rows in the most affected region. In addition, morphology of photoreceptor inner and outer segments was better preserved in tg6 mice (Fig. 2F). At $12 \mathrm{~d}$ after illumination, photoreceptor apoptosis is completed, and the remaining photoreceptors are stable (our unpublished observation). The larger survival rate of tg6 photoreceptors $12 \mathrm{~d}$ after light exposure is reflected by the increased rhodopsin content of transgenic retinas $(92 \pm 2.3 \%$ of untreated controls; $n=3$ ) as compared with wt littermates (76 \pm $12 \%$ of untreated controls; $n=3$ ).

The morphological examination of the retina identifies the area of lesion and cell types that are affected but restricts the analysis to a small tissue fraction. Therefore, we used the ELISAbased quantification of free cytoplasmic nucleosomes (as they occur during the course of apoptosis) to determine the extent of cell death in a whole retina. Measurements in light-exposed retinas of 6- to 8-week-old tg6 animals showed a reduced number of cytoplasmic nucleosomes as compared with wt mice. According

$\leftarrow$

wt (data not shown). G, Extent of light damage in retinas of $\operatorname{tg} 6$ mice at ages indicated. Damage is expressed in percentage of damage in littermate control mice of corresponding ages. Damage was determined by ELISA-based measurement of cytoplasmic nucleosomes. Values in wt were set as $100 \%$. Number of animals: $n=3-6$. Abbreviations are given in Figure 1 legend. Scale bars, $25 \mu \mathrm{m}$. 
to this number, damage was calculated to be $36 \%$ of that of wt (Fig. 2G). The reduction in damage reflects the extent of protection observed in the morphological analysis of tg6 retinas. Because photoreceptor degeneration in the inherited models occurs at an earlier age, we tested the responsiveness of younger retinas to Epo-mediated neuroprotection. The presence of the Epo transgene reduced the retinal susceptibility to light-induced degeneration and protected the photoreceptors to a similar level $(36-46 \%)$ at all ages tested (Fig. 2G). Interestingly, 3- and 4 -week-old retinas were markedly less sensitive to light than older retinas (data not shown).

Tg6 and wt littermates showed light damage only when at least one allele of the Rpe65 gene carried the Rpe $65_{450 \text { Leu }}$ variant (data not shown). The Rpe65 450 Leu variant increases steady-state levels of the RPE65 protein and the rate of rhodopsin regeneration (Wenzel et al., 2001). This observation further supports the important role of Rpe65 in the regulation of light damage susceptibility in mice. All mice used in the light damage and rhodopsin (see below) experiments were offspring from crosses between male tg6;Rpe $65_{450 \mathrm{Met}}$ and female Rpe $65_{450 \mathrm{Leu}}$ and therefore were heterozygous for the variant in the Rpe65 gene (Rpe65 $\left.5_{450 \mathrm{Met} / \mathrm{Leu}}\right)$.

Because rhodopsin regeneration is an important determinant of light damage susceptibility (Wenzel et al., 2001), we tested whether the presence of high Epo levels in the tg6 retina might influence rhodopsin regeneration in the visual cycle. Tg6 mice and wt littermates had similar dark-adapted levels of rhodopsin $(0.48 \pm 0.06 \mathrm{nmol}$ per retina for the wt and $0.48 \pm 0.03 \mathrm{nmol}$ per retina for tg6; $n=6$ retinas). Furthermore, bleaching efficiency was identical in both animals (rhodopsin remaining after a 10 min bleach: $0.05 \pm 0.01 \mathrm{nmol}$ per retina for wt and $0.05 \pm 0.01$ nmol per retina for $\operatorname{tg} 6 ; n=6$ retinas), and regeneration of rhodopsin in darkness was indistinguishable between wt and tg6 (rhodopsin levels after $45 \mathrm{~min}$ of regeneration in darkness: $0.28 \pm$ $0.03 \mathrm{nmol}$ per retina for wt and $0.26 \pm 0.05 \mathrm{nmol}$ per retina for $\operatorname{tg} 6 ; n=6$ retinas). These results strongly suggest that the presence of high Epo levels in the tg6 retina did not alter known parameters for light damage susceptibility but directly protected photoreceptor cells against apoptosis induced by acute light exposure.

\section{Effect of high Epo levels on inherited retinal degeneration}

To test a potential protective effect of Epo in inherited retinal degeneration, we crossed the Epo transgenic mice with two mouse models for human RP. The rd1 mouse carries a nonsense mutation in the gene encoding the phosphodiesterase $\beta$ subunit (Bowes et al., 1990). This induces a rapid and light-independent degeneration of the photoreceptor cell layer starting around P10. The VPP mouse carries a transgene with three mutations in the rhodopsin gene (V20G, P23H, P27L), causing a dominant but slow degeneration of the photoreceptor cell layer (Naash et al., 1993). In wt, rd1, and VPP retinas, Epo was expressed at low levels at P11 that dropped to almost nondetectable levels at P21 and at P37 (Table 1). The presence of the Epo transgene increased retinal Epo levels $>20$-fold in rd1 and VPP mice (Table 1). With increasing age, levels of Epo decreased in all groups of mice, but the presence of the transgene nevertheless sustained highly elevated Epo levels.

Similar to Epo, the Epo receptor was expressed at P11 in wt, tg6, rd1, and VPP retinas (Fig. 3A,B); however, expression of the receptor was decreased at $\mathrm{P} 21$ in both $\mathrm{rd} 1$ and VPP retinas. The levels decreased to almost nondetectable levels in the rd1 retina at P62 but remained expressed in the VPP retina. Because the Epo receptor localizes mainly to photoreceptor cells (Grimm et al.,

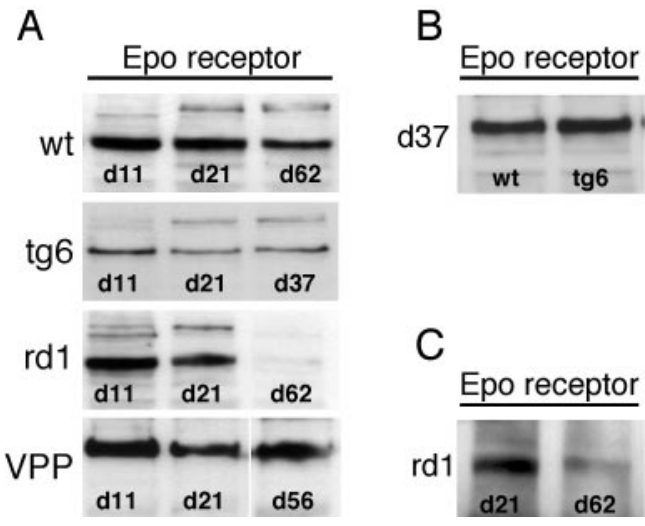

Figure 3. Expression of Epo receptor in the retina. Total retinal homogenates were tested by Western blotting for the presence of Epo receptor. $A$, Epo receptor in wt, tg6, rd1, and VPP retinas at different postnatal days as indicated. $B$, Direct comparison of Epo receptor between wt and $\operatorname{tg} 6$ retinas showing no downregulation by the overexpression of Epo in $\operatorname{tg} 6$ at least up to P37. C, Overexposure of retinal samples of rd1 mice at P21 and P62, respectively, showing a small fraction of Epo receptor remaining at $P 62$.

2002), the decrease probably reflects the loss of photoreceptors in the two mouse models (compare Figs. 4, 5). This loss is much more pronounced in the rd1 mouse with no photoreceptors left at P62 (data not shown). Thus, the remaining weak signal at P62 in the rd1 mouse (Fig. 3C) might be attributable to expression of the receptor in ganglion cells and amacrine neurons as suggested by Junk and colleagues (2002). Despite the expression of the Epo receptor at the onset of the degenerative process (P11), the presence of high levels of Epo did not rescue photoreceptors from cell death in the rd1 mouse (Fig. 4). Retinal degeneration proceeded without notable differences in $\mathrm{rd} 1$ and double-mutant $\mathrm{rd} 1 / \operatorname{tg} 6$ mice. A single layer of photoreceptor cells (mostly cones) was visible at $\mathrm{P} 21$ and $\mathrm{P} 37$.

Similarly, retinal degeneration was not influenced by the Epo transgene in the VPP mouse (Fig. 5). At 3 weeks of age, the ONL thickness in VPP and VPP/tg6 mouse lines was approximately half of that in control littermates. Degeneration proceeded slowly in both strains, and at 8 weeks of age, only one to two additional rows of photoreceptor nuclei were lost. In contrast to the decreasing number of photoreceptor cells, morphology of the inner and outer segments in the VPP and VPP/tg6 strains improved between postnatal weeks three and six. This observation was confirmed by retinal rhodopsin measurements (Fig. 6). Although rhodopsin levels in wt and tg6 strains were at normal levels throughout the experimental period, rhodopsin contents of the VPP retinas (independently of the presence or absence of the Epo transgene) were reduced at 3 weeks of age and increased until postnatal week 6 before levels decreased again.

To circumvent potential long-term side effects of the sustained Epo expression from the Epo transgene used in the above experiments (see Discussion), we repetitively injected 100 IU of recombinant huEpo intraperitoneally into $\mathrm{rd} 1$ and VPP mice at P11 (rd1 only), 13, 15, 17, and 19. The dosage used (100 IU per injection) was shown to protect retinal photoreceptors against light damage after a single injection (Grimm et al., 2002). At P21, mice were killed and analyzed. The Epo-injected mice showed hematocrit values elevated by $41 \%(\mathrm{VPP} ; n=4)$ and $40 \%$ (rd1; $n=11$ ) on average compared with sham-injected mice. This confirms that the applied Epo was biologically active; however, retinal morphology was not detectably rescued in the rd1 (Fig. $7 A$ ) and the VPP (Fig. 7B) mice, and rhodopsin levels were either 

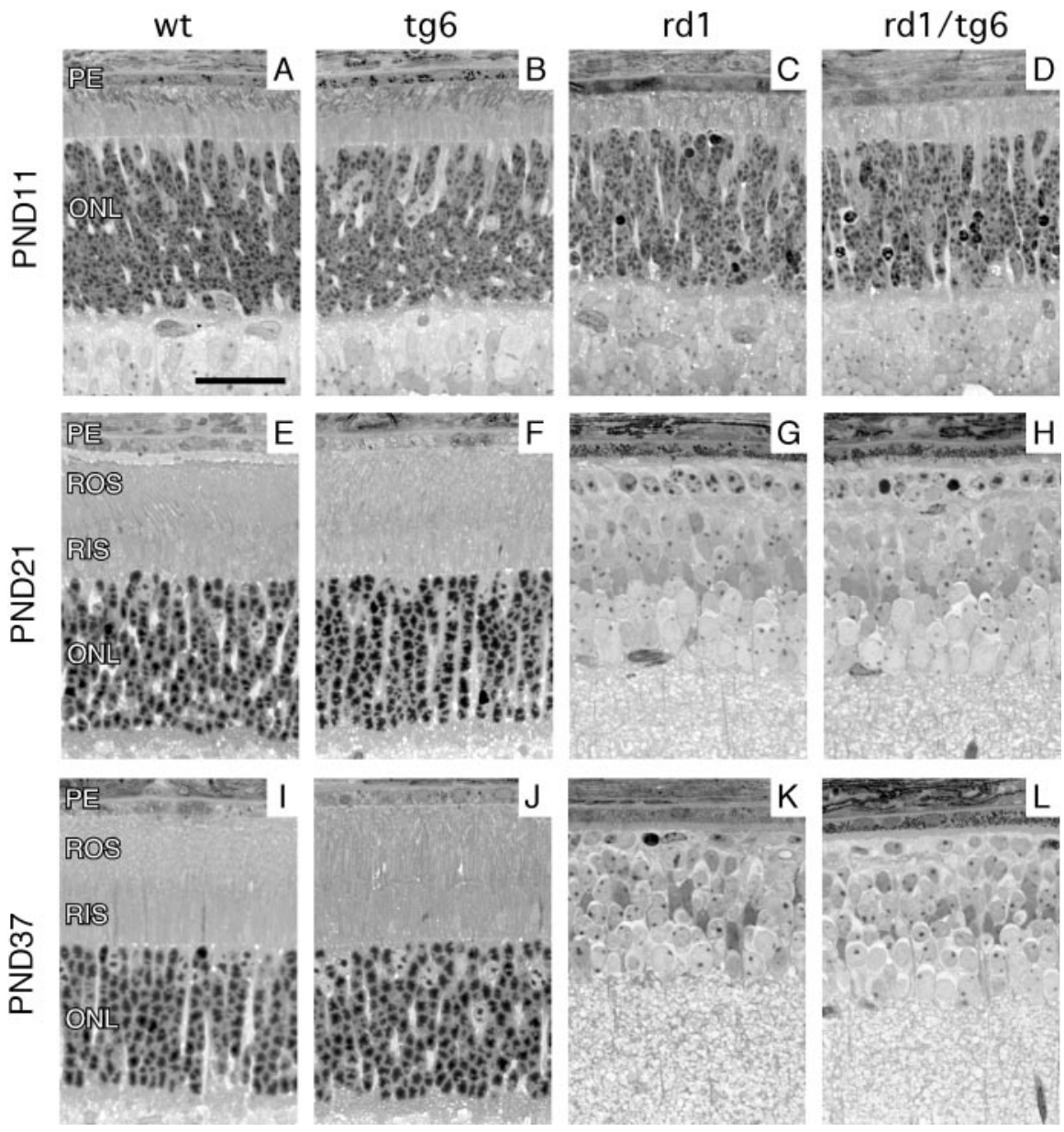

Figure 4. huEpo transgene expression does not rescue photoreceptor cells in the rd1 mouse. Retinal morphology at P11 $(A-D)$, P21 $(E-H)$, and P37 $(I-L)$ of wt $(A, E, I), \operatorname{tg} 6(B, F, J), \operatorname{rd} 1(C, G, K)$, and rd1/tg6 double-mutant mice $(D, H, L)$. Compared with wt and $\operatorname{tg} 6$ retinas, the outer segments in rd1 and $\mathrm{rd} 1 / \operatorname{tg} 6$ mice are less developed, and both $\mathrm{rd} 1 \mathrm{and} \mathrm{rd} 1 / \mathrm{tg} 6$ retinas show scattered apoptotic nuclei at P11 and almost complete loss of photoreceptors at P21 and P37. Representative sections of two to four animals per time point and mouse strain are presented. Abbreviations are given in Figure 1 legend. PND, Postnatal day. Scale bar, $25 \mu \mathrm{m}$.

not detectable (rd1; data not shown) or did not differ from untreated controls (VPP) (Fig. 7C).

\section{Discussion}

We showed recently that increased retinal levels of Epo (induced either by hypoxic preconditioning or by intraperitoneal injection of recombinant huEpo) protect the retina against degeneration induced by acute exposure to high intensity light (Grimm et al., 2002). Furthermore, Epo protected retinal ganglion cells from cell death after experimental ischemia (Junk et al., 2002). Therefore, Epo became a candidate drug for the treatment of inherited retinal degenerative diseases such as retinitis pigmentosa in human patients.

Here we show that Epo has the capacity to protect the retina against light damage also when expressed from a transgene. Thus, with regard to its neuroprotective potential, transgenically overexpressed huEpo protein is comparable with systemically applied recombinant huEpo. To test whether Epo can also protect retinal cells in inherited retinal degeneration, we crossed the transgene into two mouse models for human RP. In both the rd1 and the VPP mouse, the transgene caused highly increased levels of Epo in the retina but did not inhibit cell death and retinal degeneration. Similarly, exogenous application of huEpo also did not delay cell death in the two mouse models of human RP used. This lack of protection indicates that Epo cannot interfere with the death signal induced by the respective gene mutations.

It has been shown that increased oxygen levels (hyperoxia) slow photoreceptor death in a rat model of retinal degeneration [Royal College of Surgeons (RCS) rat] and that reduced oxygenation accelerates disease progression (Maslim et al., 1997; Valter et al., 1998). This suggests a critical role of retinal oxygen levels in the regulation of cell death. Epo-overexpressing tg6 mice have increased blood volumes (up to $25 \%$ of body weight) (Vogel et al., 2003) and hematocrit values (up to 83\%) (Ruschitzka et al., 2000) twice as high as wt mice. Because the arterial $\mathrm{P}_{\mathrm{O}_{2}}$ is not altered, the arterial oxygen content is increased, thereby implying elevated oxygenation of all organs, including the retina. Nevertheless, retinal degeneration in the rd1 and the VPP mouse was not influenced, suggesting that mechanisms different from those in the RCS rat may account for the photoreceptor cell death in the two mouse models.

Despite their highly increased blood volume and hematocrit value, tg6 mice do not show an elevated risk for thromboembolism (Wiessner et al., 2001). Obviously, the life-long exposure to high Epo levels provoked adaptative mechanisms including nitric oxide-mediated vasodilation (Ruschitzka et al., 2000; Vogel et al., 2003) as well as regulated elevation of blood viscosity by increasing erythrocyte flexibility (Quaschning et al., 2003; Shibata et al., 2003). It is therefore feasible that the prolonged exposure to high Epo levels in tg6 might possibly desensitize the Epo-Epo receptor (EpoR) system in the retina, reducing the neuroprotective capacity of Epo; however, a potential desensitization of the Epo system was not obvious in our model system. The Epo receptor was highly expressed in the retina as early as at P11 in all strains tested, and Epo receptor levels in tg6 and wt mice remained comparably high at least until day 37. Furthermore, the Epo transgene protected the retina against light damage to a similar extent, independently of the age of the animals (Fig. 2). Although retinas of young mice were less susceptible to light damage in general, the presence of high Epo levels further reduced the severity of retinal degeneration after light exposure. This shows that Epo can already confer neuroprotection in young retinas, at a time when retinal degeneration is ongoing at least in the VPP model. These results suggest that constitutively high levels of Epo did not downregulate expression of Epo receptor as an adaptative measure in the tg6 retina and that a desensitization of the EpoEpoR system did not occur.

Although Epo protects against light damage (Fig. 2) (Grimm et al., 2002), Epo did not improve photoreceptor cell survival and retinal pathology in the VPP mouse, although progression of the degeneration of the VPP retina is accelerated by light (Naash et al., 1996). Light as pathogenic stimulus uses at least two different pathways to induce the apoptotic program. Activation and choice of 
a particular pathway seem to depend on the intensity and duration of light exposure (Hao et al., 2002). Thus, a compound effective in the protection against acute bright light, such as Epo, may not necessarily be protective against long-lasting low-level light exposure. Such a prolonged exposure to low-level light may be the cofactor accelerating the degeneration mediated by the VPP mutations. Differences in signaling between light-induced and inherited retinal degeneration are also evidenced by the observed differential effect of several survival factors ( $\mathrm{La}-$ Vail et al., 1998) and other compounds such as nitro-L-arginine methyl ester (Kaldi et al., 2003) or the free radical trap phenyl- $N$-tert butylnitrone (Ranchon et al., 2003) on lightinduced and inherited retinal degeneration in mice and rats.

Different apoptotic pathways may exist in various models of retinal degeneration and a potential systemic or local adaptation to high Epo levels might affect one but not another anti-apoptotic pathway. To address such a possibility, we applied huEpo exogenously. As shown previously, intraperitoneally injected huEpo reaches the retina where it can protect the retina against light damage (Grimm et al., 2002). The repeated systemic application of huEpo increased hematocrit values of the injected animals, showing that the protein was biologically active; however, the injected Epo could not inhibit cell death in the rd1 or VPP retina. This supports the conclusion that adaptational changes, whether systemic or local, might not be the reason for the lack of protection expressed from the transgene. More likely, signaling pathways and apoptotic mechanisms differ between acute light damage and the two models of inherited retinal degeneration to such a degree that Epo can prevent cell death in one but not the other model.

It has been shown for other factors (e.g., CNTF or BDNF) that different models are amenable in different ways to a treatment with cytokines (LaVail et al., 1998). At the present time, our data suggest that Epo alone might not be sufficient for a successful therapeutic intervention with cell death in inherited retinal degeneration. On the other hand, encouraging results after Epo treatment have been reported on three patients with diabetic retinopathy and renal failure (Berman and Friedman, 1994; Friedman et al., 1995).

We observed that protection by transgenically expressed (or exogenously applied) Epo was less efficient as compared with hypoxic preconditioning, suggesting that other hypoxiainducible factors may act in concert with Epo to confer the complete protection observed after hypoxic exposure. It has been shown in other systems that treatment with a combination of growth factors or cytokines improves the retinal morphology in vivo and in vitro as compared with administration of the individual factors alone (Ogilvie et al., 2000; Caffe et al., 2001; Cao et al., 2001). Thus, the possibility exists that additional hypoxia-

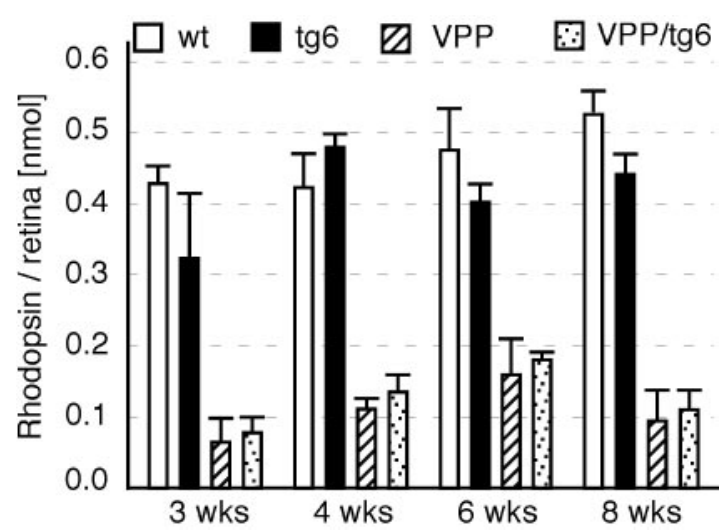

Figure 6. Effect of huEpo overexpression on rhodopsin levels (in nanomoles per retina) in wt and mutant mouse retinas at ages [weeks (wks)] indicated. Rhodopsin is representative for amount and integrity of rods. Given are mean values \pm SD of the rhodopsin content of at least $n=3$ retinas. 

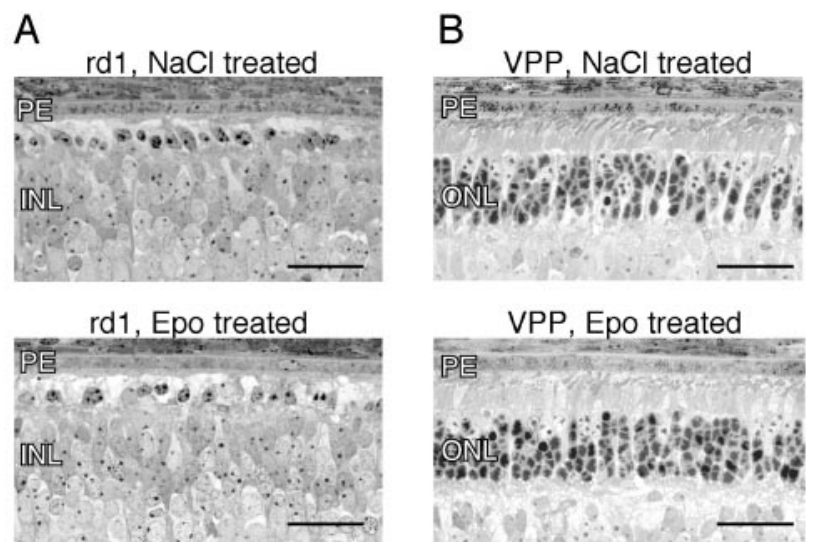

C
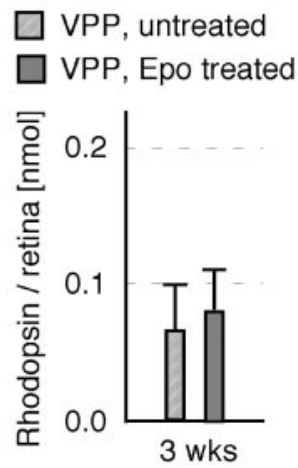

Figure 7. Effect of huEpo injections on retinal morphology and rhodopsin levels at PND 21. A, Retinal morphology of rd1 mice after NaCl injections (top panel) or Epo injections (bottom panel) applied at PND 11, 13, 15, 17, and 19. B, Retinal morphology of VPP mice after $\mathrm{NaCl}$ injections (top panel) or Epo injections (bottom panel) applied at PND 13, 15, 17, and 19. C, Rhodopsin content of VPP retinas with or without repetitive treatment (injections) of huEpo $(n=4)$. Abbreviations are given in Figure 1 legend. Scale bar, $25 \mu \mathrm{m}$.

inducible factors might act together with Epo to achieve full neuroprotection. In keeping with this, we will test whether a successful retinal treatment with Epo requires a combination with other cytokines or growth factors.

\section{References}

Adler R, Curcio C, Hicks D, Price D, Wong F (1999) Cell death in agerelated macular degeneration. Mol Vis 5:31.

Berman DH, Friedman EA (1994) Partial absorption of hard exudates in patients with diabetic end-stage renal disease and severe anemia after treatment with erythropoietin. Retina 14:1-5.

Bowers F, Valter K, Chan S, Walsh N, Maslim J, Stone J (2001) Effects of oxygen and bFGF on the vulnerability of photoreceptors to light damage. Invest Ophthalmol Vis Sci 42:804-815.

Bowes C, Li T, Danciger M, Baxter LC, Applebury ML, Farber DB (1990) Retinal degeneration in the rd mouse is caused by a defect in the beta subunit of rod cGMP-phosphodiesterase. Nature 347:677-680.

Caffe AR, Soderpalm AK, Holmqvist I, van Veen T (2001) A combination of CNTF and BDNF rescues rd photoreceptors but changes rod differentiation in the presence of RPE in retinal explants. Invest Ophthalmol Vis Sci 42:275-282.

Cao W, Tombran-Tink J, Elias R, Sezate S, Mrazek D, McGinnis JF (2001) In vivo protection of photoreceptors from light damage by pigment epithelium-derived factor. Invest Ophthalmol Vis Sci 42:1646-1652.

Chang B, Hawes NL, Hurd RE, Davisson MT, Nusinowitz S, Heckenlively JR (2002) Retinal degeneration mutants in the mouse. Vision Res 42:517-525.

Chen CK, Burns ME, Spencer M, Niemi GA, Chen J, Hurley JB, Baylor DA, Simon MI (1999a) Abnormal photoresponses and light-induced apoptosis in rods lacking rhodopsin kinase. Proc Natl Acad Sci USA 96:3718-3722.

Chen J, Simon MI, Matthes MT, Yasumura D, LaVail MM (1999b) Increased susceptibility to light damage in an arrestin knockout mouse model of Oguchi disease (stationary night blindness). Invest Ophthalmol Vis Sci 40:2978-2982.

Cideciyan AV, Hood DC, Huang Y, Banin E, Li ZY, Stone EM, Milam AH, Jacobson SG (1998) Disease sequence from mutant rhodopsin allele to rod and cone photoreceptor degeneration in man. Proc Natl Acad Sci USA 95:7103-7108.

Cruickshanks KJ, Klein R, Klein BE (1993) Sunlight and age-related macular degeneration. The Beaver Dam eye study. Arch Ophthalmol 111:514-518.

Cruickshanks KJ, Klein R, Klein BE, Nondahl DM (2001) Sunlight and the 5 -year incidence of early age-related maculopathy: the Beaver Dam eye study. Arch Ophthalmol 119:246-250.

Friedman EA, Brown CD, Berman DH (1995) Erythropoietin in diabetic macular edema and renal insufficiency. Am J Kidney Dis 26:202-208.

Goto Y, Peachey NS, Ziroli NE, Seiple WH, Gryczan C, Pepperberg DR,
Naash MI (1996) Rod phototransduction in transgenic mice expressing a mutant opsin gene. J Opt Soc Am 13:577-585.

Grimm C, Wenzel A, Hafezi F, Remé CE (2000) Gene expression in the retina: the effect of damaging light. Mol Vis 6:252-260.

Grimm C, Wenzel A, Groszer M, Mayser H, Seeliger M, Samardzija M, Bauer C, Gassmann M, Reme CE (2002) HIF-1-induced erythropoietin in the hypoxic retina protects against light-induced retinal degeneration. Nat Med 8:718-724.

Hafezi F, Grimm C, Simmen BC, Wenzel A, Reme CE (2000) Molecular ophthalmology: an update on animal models for retinal degenerations and dystrophies. $\mathrm{Br} \mathrm{J}$ Ophthalmol 84:922-927.

Hao W, Wenzel A, Obin MS, Chen CK, Brill E, Krasnoperova NV, Eversole-Cire P, Kleyner Y, Taylor A, Simon MI, Grimm C, Reme CE, Lem J (2002) Evidence for two apoptotic pathways in light-induced retinal degeneration. Nat Genet 32:254-260.

Hopfl G, Ogunshola O, Gassmann M (2004) HIFs and tumors-causes and consequences. Am J Physiol Regul Integr Comp Physiol 286:R608-623.

Junk AK, Mammis A, Savitz SI, Singh M, Roth S, Malhotra S, Rosenbaum PS, Cerami A, Brines M, Rosenbaum DM (2002) Erythropoietin administration protects retinal neurons from acute ischemia-reperfusion injury. Proc Natl Acad Sci USA 99:10659-10664.

Kaldi I, Dittmar M, Pierce P, Anderson RE (2003) L-NAME protects against acute light damage in albino rats, but not against retinal degeneration in P23H and S334ter transgenic rats. Exp Eye Res 76:453-461.

Kueng-Hitz N, Grimm C, Lansel N, Hafezi F, He L, Fox D, Remé CE, Niemeyer G, Wenzel A (2000) The retina of c-fos $+/+$ and c-fos- $-/-$ mice: electrophysiological, morphological and biochemical aspects. Invest Ophthalmol Vis Sci 41:909-916.

LaVail MW, Yasumura D, Matthes MT, Lau Villacorta C, Unoki K, Sung CH, Steinberg RH (1998) Protection of mouse photoreceptors by survival factors in retinal degenerations. Invest Ophthalmol Vis Sci 39:592-602.

LaVail MM, Gorrin GM, Yasumura D, Matthes MT (1999) Increased susceptibility to constant light in $\mathrm{nr}$ and pcd mice with inherited retinal degeneration. Invest Ophthalmol Vis Sci 40:1020-1024.

Maslim J, Valter K, Egensperger R, Hollander H, Stone J (1997) Tissue oxygen during a critical developmental period controls the death and survival of photoreceptors. Invest Ophthalmol Vis Sci 38:1667-1677.

Mervin K, Stone J (2002) Regulation by oxygen of photoreceptor death in the developing and adult C57BL/6J mouse. Exp Eye Res 75:715-722.

Naash MI, Hollyfield JG, al-Ubaidi MR, Baehr W (1993) Simulation of human autosomal dominant retinitis pigmentosa in transgenic mice expressing a mutated murine opsin gene. Proc Natl Acad Sci USA 90:5499-5503.

Naash ML, Peachey NS, Li ZY, Gryczan CC, Goto Y, Blanks J, Milam AH, Ripps H (1996) Light-induced acceleration of photoreceptor degeneration in transgenic mice expressing mutant rhodopsin. Invest Ophthalmol Vis Sci 37:775-782.

Ogilvie JM, Speck JD, Lett JM (2000) Growth factors in combination, but not individually, rescue rd mouse photoreceptors in organ culture. Exp Neurol 161:676-685.

Organisciak DT, Li M, Darrow RM, Farber DB (1999) Photoreceptor cell damage by light in young Royal College of Surgeons rats. Curr Eye Res 19:188-196.

Portera Cailliau C, Sung CH, Nathans J, Adler R (1994) Apoptotic photoreceptor cell death in mouse models of retinitis pigmentosa. Proc Natl Acad Sci USA 91:974-978.

Quaschning T, Ruschitzka F, Stallmach T, Shaw S, Morawietz H, Goettsch W, Hermann M, Slowinski T, Theuring F, Hocher B, Luscher TF, Gassmann M (2003) Erythropoietin-induced excessive erythrocytosis activates the tissue endothelin system in mice. FASEB J 17:259-261.

Ranchon I, LaVail MM, Kotake Y, Anderson RE (2003) Free radical trap phenyl- $N$-tert-butylnitrone protects against light damage but does not 
rescue $\mathrm{P} 23 \mathrm{H}$ and $\mathrm{S} 334$ ter rhodopsin transgenic rats from inherited retinal degeneration. J Neurosci 23:6050-6057.

Remé CE, Grimm C, Hafezi F, Marti A, Wenzel A (1998) Apoptotic cell death in retinal degenerations. Prog Ret Eye Res 17:443-464.

Ruschitzka FT, Wenger RH, Stallmach T, Quaschning T, de Wit C, Wagner K, Labugger R, Kelm M, Noll G, Rulicke T, Shaw S, Lindberg RL, Rodenwaldt B, Lutz H, Bauer C, Luscher TF, Gassmann M (2000) Nitric oxide prevents cardiovascular disease and determines survival in polyglobulic mice overexpressing erythropoietin. Proc Natl Acad Sci USA 97:11609-11613.

Sanyal S, Hawkins RK (1986) Development and degeneration of retina in rds mutant mice: effects of light on the rate of degeneration in albino and pigmented homozygous and heterozygous mutant and normal mice. Vision Res 26:1177-1185.

Shibata J, Hasegawa J, Siemens HJ, Wolber E, Dibbelt L, Li D, Katschinski DM, Fandrey J, Jelkmann W, Gassmann M, Wenger RH, Wagner KF (2003) Hemostasis and coagulation at a hematocrit level of 0.85: functional consequences of erythrocytosis. Blood 101:4416-4422.

Simons K (1993) Artificial light and early-life exposure in age-related macular degeneration and in cataractogenic phototoxicity. Arch Ophthalmol 111:297-298.

Taylor HR, Munoz B, West S, Bressler NM, Bressler SB, Rosenthal FS (1990) Visible light and risk of age-related macular degeneration. Trans Am Ophthalmol Soc 88:163-173.
Valter K, Maslim J, Bowers F, Stone J (1998) Photoreceptor dystrophy in the RCS rat: roles of oxygen, debris, and bFGF. Invest Ophthalmol Vis Sci 39:2427-2442.

Vogel J, Kiessling I, Heinicke K, Stallmach T, Ossent P, Vogel O, Aulmann M, Frietsch T, Schmid-Schonbein H, Kuschinsky W, Gassmann M (2003) Transgenic mice overexpressing erythropoietin adapt to excessive erythrocytosis by regulating blood viscosity. Blood 102:2278-2284

Wagner KF, Katschinski DM, Hasegawa J, Schumacher D, Meller B, Gembruch U, Schramm U, Jelkmann W, Gassmann M, Fandrey J (2001) Chronic inborn erythrocytosis leads to cardiac dysfunction and premature death in mice overexpressing erythropoietin. Blood 97:536-542.

Wang M, Lam TT, Tso MO, Naash MI (1997) Expression of a mutant opsin gene increases the susceptibility of the retina to light damage. Vis Neurosci 14:55-62.

Wenzel A, Remé CE, Williams TP, Hafezi F, Grimm C (2001) The Rpe65 Leu450Met mutation increases retinal resistance against light-induced degeneration by slowing rhodopsin regeneration. J Neurosci 21:53-58.

Wiessner C, Allegrini PR, Ekatodramis D, Jewell UR, Stallmach T, Gassmann M (2001) Increased cerebral infarct volumes in polyglobulic mice overexpressing erythropoietin. J Cereb Blood Flow Metab 21:857-864.

Wong P (1994) Apoptosis, retinitis pigmentosa, and degeneration. Biochem Cell Biol 72:489-498. 